\title{
Effects of Thermal Spiking on Graphite-Epoxy Composites
}

\author{
Alfred C. Loos and George S. Springer \\ Department of Mechanical Engineering \\ The University of Michigan \\ Ann Arbor, Michigan 48109
}

(Received November 28, 1978)

\begin{abstract}
Tests were performed evaluating the effects of thermal spikes on the moisture absorption characteristics, the ultimate tensile strength, and the buckling modulus of Thornel 300/Fiberite 1034 composites. Measurements were made on unidirectional and $\pi / 4$ laminates, using different types of thermal spikes. A survey was also made of the existing data. This survey, together with the present data indicate how thermal spikes affect the moisture absorption and the mechanical properties of different graphite-epoxy composites.
\end{abstract}

\section{INTRODUCTION}

$\mathbf{O}$ NE OF THE questions in practical applications of composite materials is the degradation of the material due to exposure to a moist environment. Moisture absorbed by the material may have undesirable effects resulting in a reduction in mechanical properties. The environment may be especially damaging if the temperature is not constant but varies rapidly over a wide range. Sudden, large temperature changes, referred to as "thermal spikes", are encountered for example by aircraft flying at supersonic speeds.

Thermal spikes may alter significantly the moisture absorption as well as the mechanical properties of composite materials. For this reason, numerous investigators have been concerned with the effects of thermal spikes on material behavior. A summary of recent investigations is given in Table 1. Although the experimental results indicate that the changes caused by thermal spikes depend upon the characteristics of the spike, the dependence of material response on the thermal spike characteristics has not yet been explored in detail. The objective of this investigation was, therefore, to evaluate the relationships between material behavior and such thermal spike variables as maximum and minimum temperatures during the 
Table 1. Summary of Experimental Data on the Effects of Thermal Spikes on Graphite-Epoxy Composites

\begin{tabular}{|c|c|c|c|c|c|c|c|c|c|}
\hline Material & Reference & $\begin{array}{l}\text { Absorption } \\
\text { Behavior }\end{array}$ & $\begin{array}{l}\text { Tensile } \\
\text { Strength }\end{array}$ & $\begin{array}{l}\text { Compres- } \\
\text { sion } \\
\text { Strength }\end{array}$ & $\begin{array}{l}\text { Shear } \\
\text { Strength }\end{array}$ & $\begin{array}{l}\text { Flexural } \\
\text { Strength }\end{array}$ & $\begin{array}{l}\text { Buckling } \\
\text { Modulus }\end{array}$ & $\begin{array}{l}\text { Tensile } \\
\text { Modulus }\end{array}$ & Fatigue \\
\hline $\mathrm{T} 300 / 1034$ & Present work & $\mathrm{N}$ & $\mathrm{N}$ & & & & $\mathrm{N}$ & & \\
\hline T300/934 & $\begin{array}{l}\text { Bohlmann-Dergy [1] } \\
\text { Reinhart [2] }\end{array}$ & $\underset{N}{N}$ & & & & & & & \\
\hline \multirow[t]{4}{*}{ T300/5208 } & McKague et al [3] & $\mathrm{l}$ & & & & & & & \\
\hline & Kibler $[4]$ & L & & & & & & & \\
\hline & Augl $[5]$ & & & & & $\mathrm{N}$ & & & \\
\hline & Lundemo-Thor [6] & & $\mathrm{S}$ & & & & & & L \\
\hline T300/5209 & Stoecklin* [7] & & $s$ & $\mathrm{~N}$ & $\mathbf{N}$ & $\mathrm{S}$ & & & \\
\hline $\mathrm{T} 300 / 2544$ & Stoecklin* $[7]$ & & $\mathrm{s}$ & $\mathrm{s}$ & $\mathrm{S}$ & $\mathbf{S}$ & & & \\
\hline $\mathrm{T} 400 / 2544$ & Trabocco-Stander $* 8]$ & & $\mathrm{N}-\mathrm{L}$ & $s$ & $\mathrm{~N}$ & & & & \\
\hline \multirow[t]{2}{*}{$\mathrm{AS} / 3501$} & Stoecklin* ${ }^{[7]}$ & & $\mathrm{s}$ & $\mathbf{S}$ & $\mathrm{N}$ & & & & \\
\hline & Trabocco-Stander ${ }^{*}[8]$ & & & N & & & & & \\
\hline AS/3501-5 & Delsai-Whiteside [9] & $\mathrm{N}$ & & & & & & & \\
\hline AS/X-2546 & Browning-Hartness $[10]$ & & & & & $\mathbf{L}$ & & & \\
\hline HMS $/ 339$ & Camahort et al [11] & $\mathrm{N}$ & & & & & $\mathrm{N}$ & & \\
\hline HMS/934 & Camahort et al $[11]$ & $\mathrm{S}$ & & & & & $\mathrm{N}$ & & \\
\hline HMS6759 & Camahort et al [11] & $\mathrm{s}$ & & & & & & $\mathbf{N}$ & \\
\hline HMS/3501 & Camahort et al $[11]$ & $\mathrm{N}$ & & & & & & $\mathrm{N}$ & \\
\hline HMS/X-2546 & Browning-Hartness $[10]$ & & & & & L & & & \\
\hline HTS/3002 & Trabocco-Stander ${ }^{*}[8]$ & & & & $\mathrm{N}$ & & & & \\
\hline HTS/4617 & Browning-Hartness $[10]$ & & $\mathrm{N}$ & $\mathrm{N}$ & s & & & & \\
\hline HTS/ADX 516 & Browning-Hartness [10] & & $\mathrm{N}$ & $\mathrm{N}$ & $\mathrm{s}$ & & & & \\
\hline HTS/P $13 \mathrm{~N}$ & Browning-Hartness $[10]$ & & $\mathrm{N}$ & $\mathrm{N}$ & $\mathrm{s}$ & & & & \\
\hline HTS/X-2546 & Browning-Hartness $[10]$ & & $\mathrm{N}$ & L & & $\mathbf{L}$ & & & \\
\hline \multicolumn{2}{|c|}{ Modmor II/5206 Trabocco-Stander* [8] } & & & & $\mathrm{N}$ & & & & \\
\hline Narmco $2387(\mathrm{nr}$ & r) Browning-Hartness [10] & & $\mathrm{L}$ & & & & & & \\
\hline ERL 2256(nr) & Browning-Hartness $[10]$ & & $\mathrm{s}$ & & & & & & \\
\hline ERLA $4617(n r)$ & Browning-Hartness $[10]$ & & $\mathrm{L}$ & & & & & & \\
\hline $\mathrm{X} 2546(\mathrm{nr})$ & Browning-Hartness $[10]$ & & $\mathrm{L}$ & & & & & & \\
\hline
\end{tabular}

$\mathrm{N}$ - negligible effect; $\mathrm{S}$ - small effect; $\mathrm{L}$ - large effect; (nr) neat resin; * - weathering test

spike, rate of temperature increase and decrease, duration of the spike, and number of spikes. The effects of these variables on moisture content, the diffusion coefficient, the tensile strength, and the buckling modulus were examined for Thornel 300/Fiberite 1034 graphite-epoxy composites.

\section{THERMAL SPIKES}

Two thermal spiking sequences were employed, these being designated as "intermittent" spiking and "continuous" spiking. In intermittent spiking the material was remoisturized between subsequent spikes. In continuous spiking the material was exposed repeatedly to thermal spikes without being remoisturized between the spikes. The steps of each spiking sequence are described below.

\section{1) Intermittent Spiking}

Intermittent spiking was performed in the following sequence (Figure 1)

a) The material was oven dried at $394 \mathrm{~K}$. 
b) The material was exposed to humid air (100\% relative humidity, $366 \mathrm{~K})$ until it became fully saturated.

c) The material was cooled to $297 \mathrm{~K}$ and was then exposed to one thermal spike.

d) The material was remoisturized in humid air ( $100 \%$ relative humidity, $366 \mathrm{~K}$ ) until the maximum saturation level was reached as in step $b$.

Septs $c$ and $d$ were repeated until the required number of spikes were completed (spike N, Figure 1). Upon completion of the last (Nth) spike the following two steps were taken

e) The material was oven dried at $394 \mathrm{~K}$.

f) The material was remoisturized in humid air ( $100 \%$ relative humidity, $366 \mathrm{~K})$ until the maximum saturation level was reached.

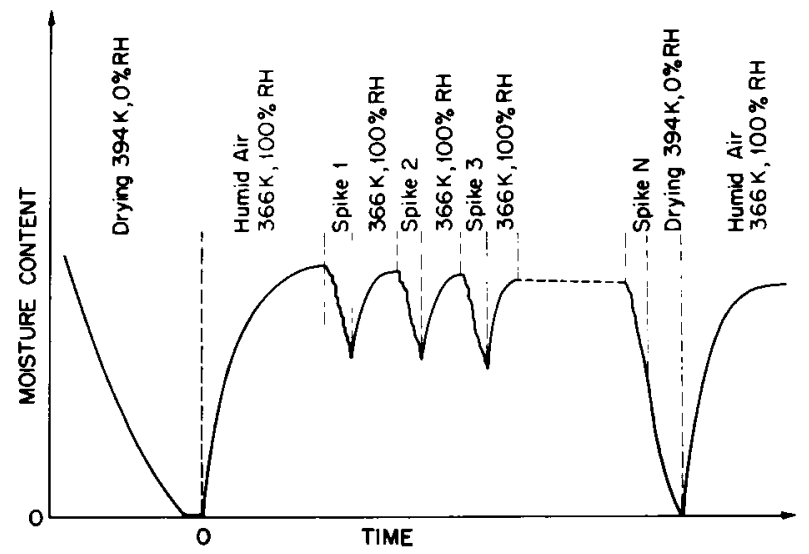

Figure 1. Intermittent spiking sequence.

The above procedure was performed with either a "fast" spike or a "slow" spike (Figure 2). For both of these spikes the temperature ranged from a minimum of $297 \mathrm{~K}$ to a maximum of $450 \mathrm{~K}$. The differences between the fast and slow spikes were in the duration the material was exposed to the maximum spike temperature and in the rate of change of temperature. During the fast spike the material was placed into a dry oven preheated to $450 \mathrm{~K}$. At the end of 5 minutes the material was removed from the oven. During the slow spike the material was placed into a dry oven at $297 \mathrm{~K}$. The oven temperature was then gradually increased for 25 minutes, maintained constant for 10 minutes, and decreased gradually for 40 minutes, as illustrated in Figure 2.

The following parameters were measured: 1) maximum moisture content, 2) transverse diffusivity, 3) tensile strength, and 4) buckling modulus. These parameters were measured before the first spike, after 1,2,5 and 10 spikes (for both the fast and the slow spikes) and after 20 spikes for fast and after 15 spikes for slow spikes. The mechanical measurements were always made after the test specimen was remoisturized (step $d$ above) so that the moisture content of each specimen was the same during the measurements. Every test was performed with different specimens. The six conditions thus required six sets of specimens for each of the four parameters tested. 

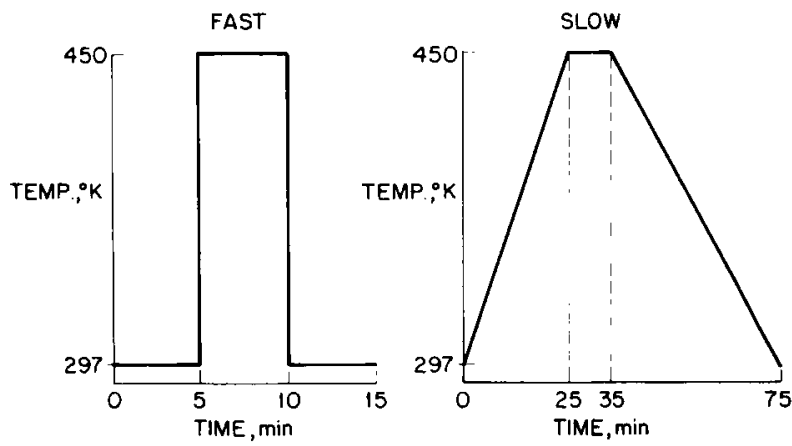

Figure 2. Thermal spikes used in intermittent spiking program.

\section{2) Continuous Spiking}

Continuous spiking was performed in the following sequence (Figure 3)

a) The material was oven dried at $366 \mathrm{~K}$.

b) The material was either spiked immediately (Figure 3 left) or was immersed in humid air ( 100 percent relative humidity, $344 \mathrm{~K}$ ) until the maximum saturation level was reached (Figure 3 right). Thus, prior to being spiked the material was either dry or was fully saturated.

c) The material was spiked repeatedly in the manner described below.

d) The material was oven dried at $366 \mathrm{~K}$.

e) The material was placed into an environmental chamber and remoisturized either in humid air $(100 \%$ relative humidity, $344 \mathrm{~K})$ or in saturated steam at $422 \mathrm{~K}$.
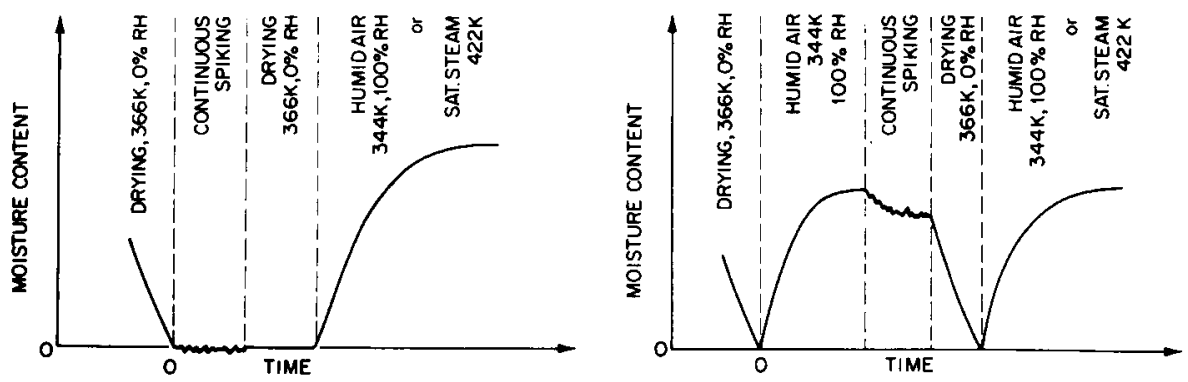

Figure 3. Continuous spiking sequence. Material at maximum saturation level prior to spiking (right). Material dry before spiking (left). 
The thermal spiking was accunplished by alternately placing the specimens into two reservoirs maintained at different temperatures. The specimens were kept for three minutes in each reservoir and were moved from one reservoir to the other without delay. Three constant temperature reservoirs at $195 \mathrm{~K}, 294 \mathrm{~K}$, and $422 \mathrm{~K}$ were used to obtain the following temperature combinations

$$
\begin{aligned}
& 195 \mathrm{~K}-422 \mathrm{~K} \\
& 195 \mathrm{~K}-294 \mathrm{~K} \\
& 294 \mathrm{~K}-422 \mathrm{~K}
\end{aligned}
$$

The specimens were spiked either once, five times, or twenty-five times. Different sets of specimens were used for each test. The two initial conditions (specimen dry or fully sautrated), the three temperature combinations (see above), the three different numbers of spikes $(1,5$ or 25$)$ and the two saturation conditions after spiking (humid air or saturated steam) thus required 36 sets of specimens.

The weight change of the material as a function of time was measured before and after the spiking.

\section{SPECIMENS IMMERSED IN SATURATED STEAM}

In order to evaluate the effects of immersion in saturated steam, both unidirectional and $\pi / 4$ specimens were oven dried and then exposed to saturated steam at $422 \mathrm{~K}$. The weight change of these specimens as a function of exposure time was monitored. In addition, the tensile strengths and buckling moduli of the specimens were measured before immersion and after $139,278,348,435$, and 529 hours of exposure to saturated steam.

\section{EXPERIMENTAL}

All data reported in this paper were obtained using specimens cut from 8 ply Thornel 300/Fiberite 1034 autoclave cured panels. The panels were fabricated from $30.5 \mathrm{~cm}$ prepreg (Fiberite Corp.) using standard layup and vacuum bagging procedures. The cure cycle used in manufacturing the panels is given in the Appendix. Both unidirectional $\left(0^{\circ}\right)$ and $\pi / 4$ specimens were used, the symbol $\pi / 4$ denoting a layup with $(0 / \pm 45 / 90)_{S}$ fiber orientations.

The specimens used for measuring weight gain as a function of time were 100 $\mathrm{mm}$ long, $12.7 \mathrm{~mm}$ wide, and $0.91 \mathrm{~mm}$ thick. The dimensions of the specimens used in the tensile tests are shown in Figure 4. The buckling tests were made with $0.91 \mathrm{~mm}$ thick and $4.95 \mathrm{~mm}$ wide specimens, ranging in length from 56 to $173 \mathrm{~mm}$.

The maximum moisture content $M_{m}$ and the transverse diffusivity $D$ were determined from the measured weight gain versus time curves according to the procedure described in Reference 12. The ultimate tensile strength and the buckling modulus were measured using a 10,000 lb capacity Instron machine (Model TTCLM 1-4) at a cross head speed of $1.27 \mathrm{~mm} \mathrm{~min}$. The buckling moduli were determined using the procedure given by Shen and Springer [13]. Both the tensile and the buckling 
(a)

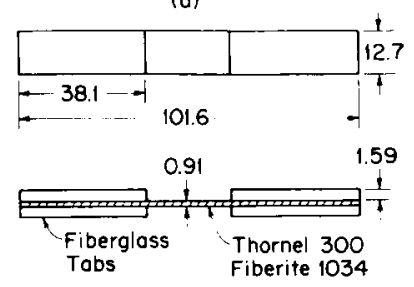

(b)
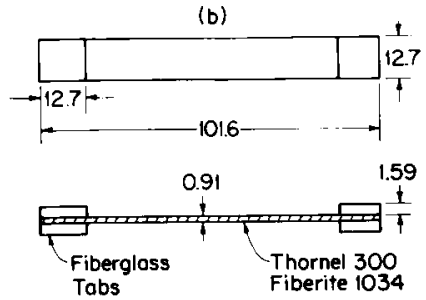

Figure 4. Geometry of tensile test specimens, $0^{\circ}$ laminates (top) $\pi / 4$ laminates (bottom). All dimensions in $\mathrm{mm}$. tests were made at room temperature $(297 \mathrm{~K})$. Every data point presented in the following section is the average of three measurements.

\section{RESULTS}

\section{1) Intermittent Spiking}

The data obtained with intermittent spiking are presented in Figures 5-8. As is seen from Figure 5 the maximum moisture content $M_{m}$ remained unchanged through 20 fast and 15 slow spikes. The transverse diffusivity $D$ was also unaffected by the spiking (Figure 6). It is concluded, therefore, that the moisture absorption characteristics of Thornel 300/Fiberite 1034 do not change appreciably with spiking, as long as the spiking conditions are within the limits of the present tests.

In Figures 9 and 10 photomicrographs of unidirectional and $\pi / 4$ specimens are shown after 20 fast and 15 slow spikes. The micrographs indicate that no cracks have developed in the microstructure of unidirectional and $\pi / 4$ specimens after 20 fast spikes (Figure 9) or in unidirectional specimens after 15 slow spikes (Figure 10, bottom). The micrograph of the $\pi / 4$ specimen after 15 slow spikes shows that cracks are present in the composite structure. However, these cracks did not seem to affect appreciably either $M_{m}$ or $D$.

It is noted that the diffusivities of the unidirectional and the $\pi / 4$ composites are expected to be nearly the same [12]. The small differences in the observed diffusivities may have been due to unintentional differences in the curing processes of the two materials. Slight differences during curing may result in different diffusivities. This is illustrated in Figure 11, where the moisture contents of two sets of Hercules AS/3501-5 graphite epoxy specimens are compared. The two sets were from the same panel. The panel was post-cured in two sections, with both sections post-cured simultaneously in the same oven. As can be seen the moisture contents (as well as $M_{m}$ and $D$ ) for the two panels are considerably different even though the curing conditions were ostensibly the same for both panels.

The higher diffusivities of the $\pi / 4$ specimens (see Figure 6 ) may also have been caused by moisture diffusion along the fiber-matrix interfaces. There are many more of these interfaces exposed to the environment around the edges of $\pi / 4$ specimens than around the edges of unidirectional specimens. 


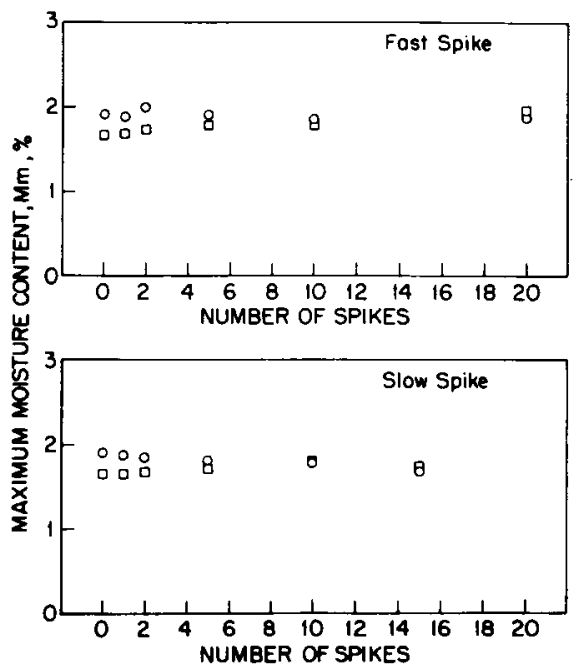

Figure 5. Maximum moisture content, $M_{m}$ versus number of intermittent spikes, T300/Fiberite 1034. o- unidirectional laminates; $\square-\pi / 4$ laminates.

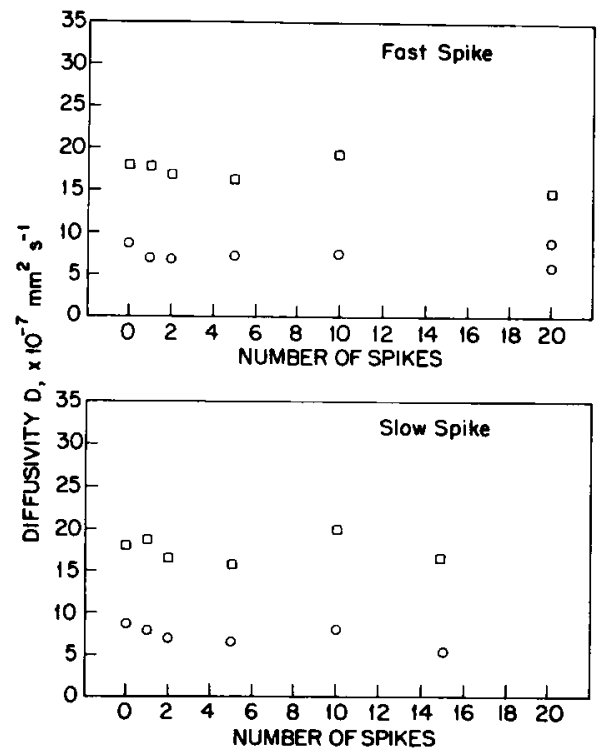

Figure 6. Transverse diffusivity, $D$ versus number of intermittent spikes, T300/Fiberite 1034. $\circ-$ unidirectional laminates; $\square-\pi / 4$ laminates. 


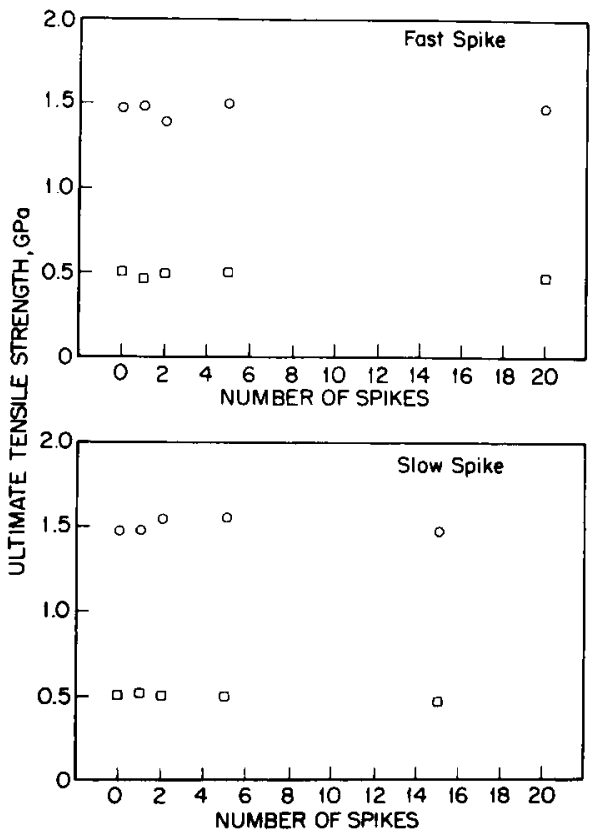

Figure 7. Ultimate tensile strength versus num. ber of intermittent spikes, T300/Fiberite 1034. ○- unidirectional laminates; $\square-\pi / 4$ laminates.

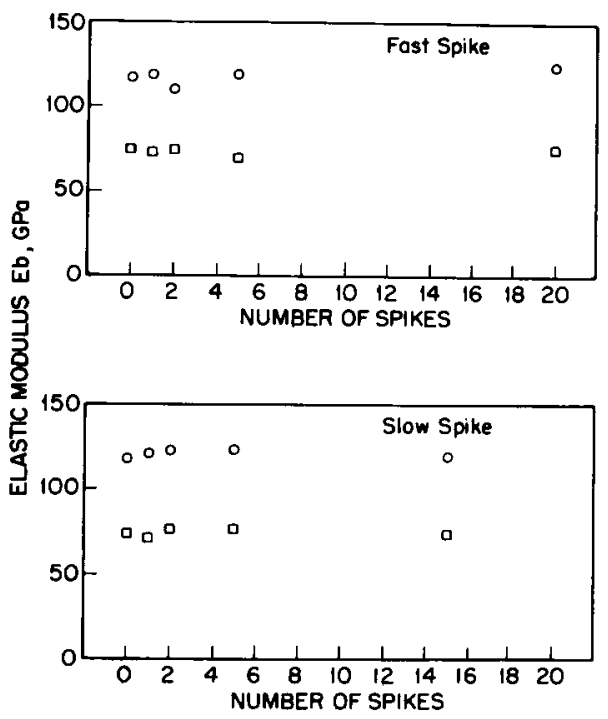

Figure 8. Elastic (buckling) modulus, $E_{b}$ versus number of intermittent spikes, T300/Fiberite 1034. O - unidirectional laminates; $\square-\pi / 4$ laminates. 

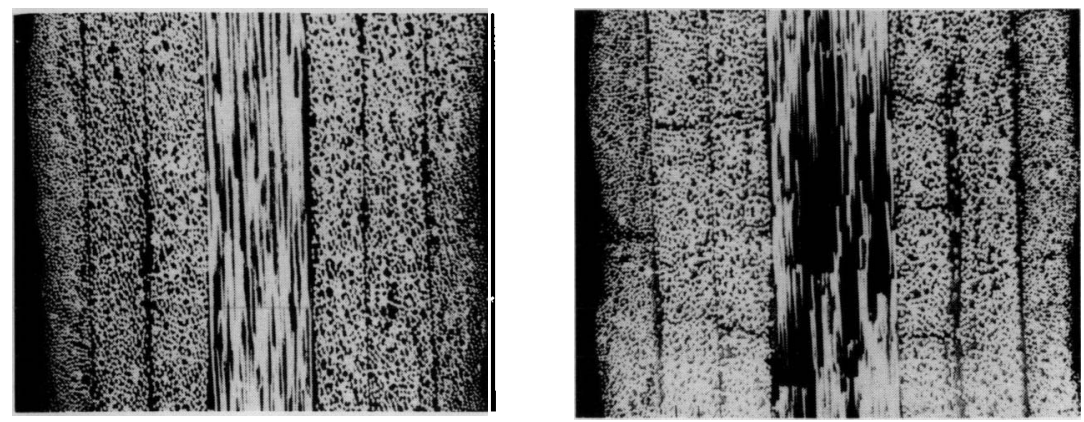

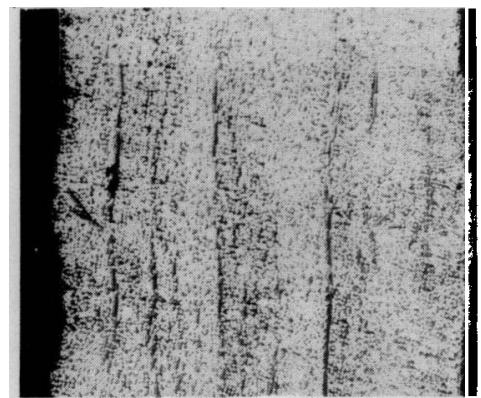

Figure 9. Photomicrographs of T300/Fiberite 1034 specimens after 20 fast intermittent spikes. Unidirectional laminate (bottom). $\pi / 4$ laminate (top) (End view, $58 X)$.

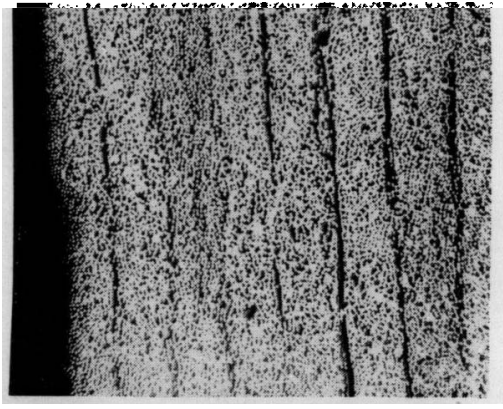

Figure 10. Photomicrographs of T300/ Fiberite 1034 specimens after 15 slow intermittent spikes. Unidirectional laminate (bottom). $\pi / 4$ laminate (top). (End view, $58 X)$.

Although the diffusivity did not change with spiking, interestingly the diffusivity did increase 50 to 75 percent after the material was once moisturized and then dried. Changes in diffusivity (and also in maximum moisture content) after one moisturization were also observed by Whitney and Browning [14] with Hercules AS/3501-5 composites. Subsequent moisturizations or spiking did not affect the diffusivity. This increase in $D$ after one moisturization may have been caused also by postcuring resulting from drying after the first moisturization.

Since neither the maximum moisture content nor the diffusivity changed with spiking, the tensile strength and the buckling modulus were expected to remain constant too. The data in Figures 7 and 8 show this to be indeed the case. The spiking did not affect the tensile strength and the buckling modulus of either the unidirectional or the $\pi / 4$ composites. 


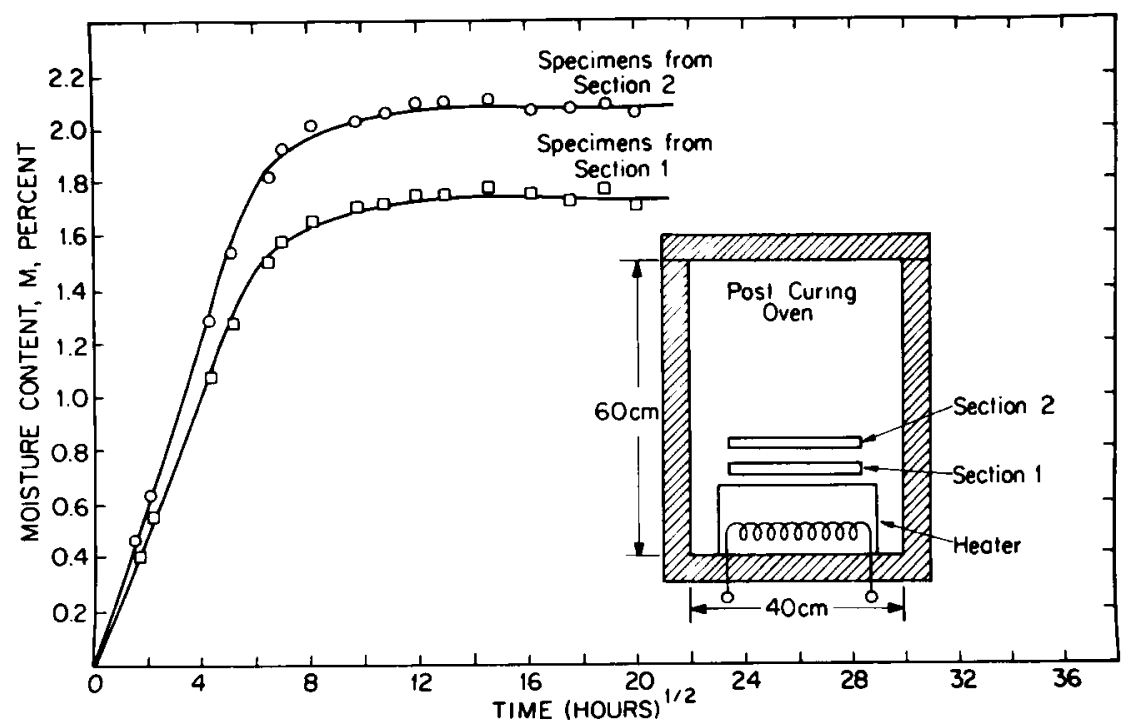

Figure 11. Moisture absorption of graphite AS/3501-5 specimens cut from two sections of the same panel, and postcured in the same oven. Distance between the two panels 0.5 $\mathrm{cm}$. Temperature monitored by thermocouples mounted on the surfaces of both panels.

\section{2) Weight Change as a Function of Time}

Before subjecting the specimens to continuous spiking, the weight change of the material as a function of time was determined for the following two cases: a) dry specimens were immersed in humid air maintained at $344 \mathrm{~K}$ and 100 percent relative humidity, and b) dry specimens were placed into a steam chamber containing saturated steam at $422 \mathrm{~K}$. These tests were performed with unidirectional specimens. The weight changes as a function of time are given in Figure 12. The weight change of the material immersed in the humid air behaved as expected (Figure 12 Bottom). The weight change first increased nearly linearly with (time $)^{1 / 2}$, then levelled off at longer times. In this case the weight change was likely due only to moisture absorbed by the material. Hence the weight change represents the moisture content of the material.

Specimens placed into the steam chamber exhibited an unexpected and unusual behavior (Figure 12 Top). Initially the weight change again increased linearly with (time $)^{1 / 2}$, but then nearly levelled off for only a brief period. Instead of remaining constant, the weight change rose abruptly and then decreased sharply. Eventually (after about 60 days) the weight of the specimens became less than their original weight. The following is a plausible explanation of this phenomenon. At first moisture enters the material. This moisture, expanding due to the heat but unable to escape because of the high moisture content of the environment results in micro- 

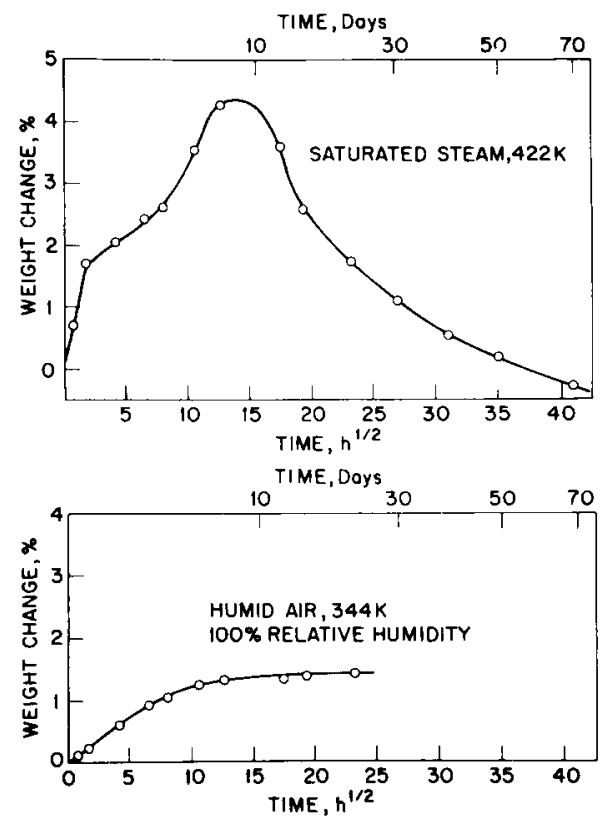

Figure 12. Weight change as a function of time of unidirectional T300/Fiberite 1034 specimens immersed in saturated steam (top) or in humid air (bottom). o-data; - fit to data.

cracks. These microcracks are clearly visible in photomicrographs taken of specimens placed inside the steam chamber (Figure 13). As these cracks develop moisture rapidly enters the material, causing the increase in weight. As further cracks develop, material, most likely in the form of resin particles, is actually lost. During this material loss moisture may still be entering the material. As long as the moisture gain is greater than the material loss the weight of the specimen increases. Once the weight of the lost material exceeds the weight of the absorbed moisture the weight of the specimen decreases. Of course when material is lost the measured weight change no longer corresponds to the moisture content of the material.

It is important to note that the phenomenon shown in Figure 12 Top and described above has been observed to occur only when the environment is both at a high temperature and at a high moisture content. Even fully saturated specimens do not exhibit such behavior when placed into a high temperature but dry environment. If the ambient moisture content is low the moisture can apparently diffuse out of the material at a rate which is sufficient to prevent the build-up of crackproducing stresses. This is a useful observation since the ambient moisture content (relative humidity) is usually low at high temperatures. 

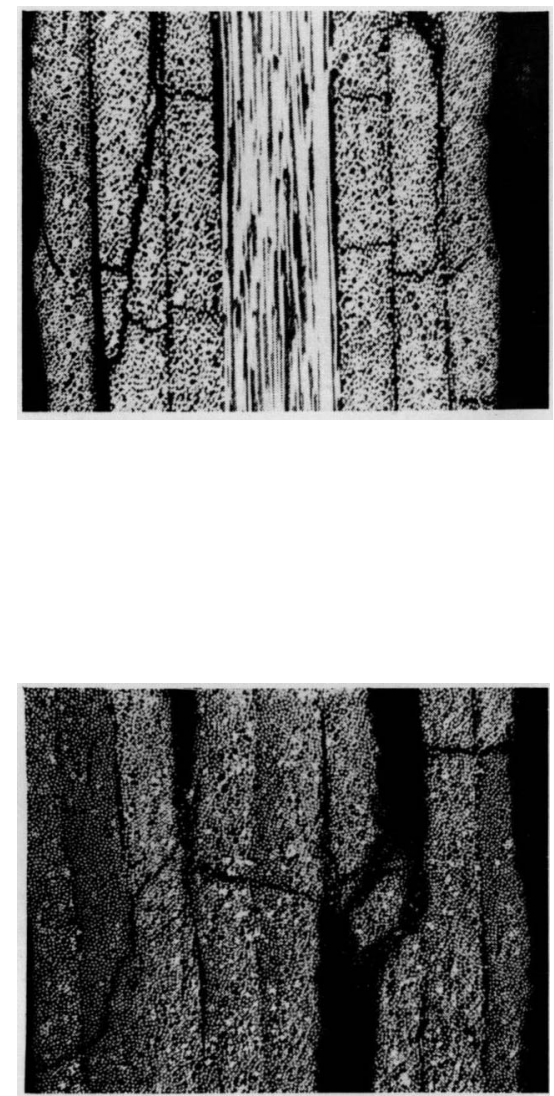

Figure 13. Photomicrographs of T300/Fiberite 1034 specimens exposed to saturated steam $(422 \mathrm{~K})$ for 22 days. Unidirectional laminate (bottom). $\pi / 4$ laminate (top). (End view, $58 X$ ).

\section{3) Continuous Spiking}

The weight changes as a function of time after one, five, or twenty-five continuous spikes are presented in Figures 14-17. For comparison the weight change as a function of time in the absence of spikes is also included in these figures (solid lines). Similar to intermittent spiking (see Section VI), continuous spiking did not seem to affect the moisture absorption characteristics of the material. The weight change exhibited the same characteristics regardless of whether or not the specimens were spiked. This was the case even when the material was placed in the steam chamber after spiking (Figures 16-17). The increase and subsequent decrease of the weight in this case was not caused by the spiking but by exposure to saturated steam, as discussed in the previous section. 


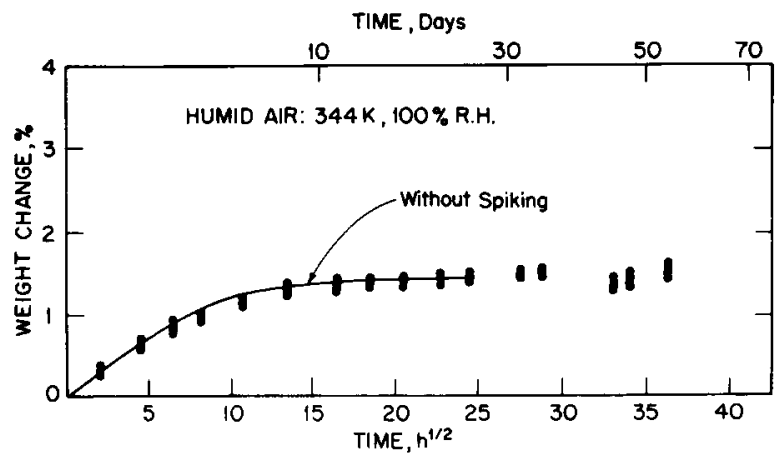

Figure 14. Weight change as a function of time of unidirectional T300/Fiberite 1034 specimens immersed in humid air after continuous spiking. Specimens were dry before spiking (see Figure 3, left). - - data for specimens spiked, 1, 5, or 25 times between the temperatures $195 \mathrm{~K}$ to $422 \mathrm{~K}, 195 \mathrm{~K}$ to $294 \mathrm{~K}$, or $294 \mathrm{~K}$ to $422 \mathrm{~K}$; solid line represents weight change of unspiked specimens.

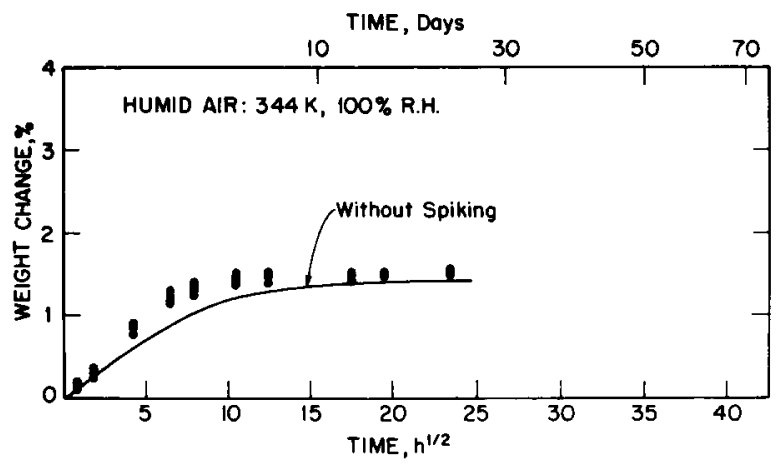

Figure 15. Weight change as a function of time of unidirectional T300/Fiberite 1034 specimens immersed in humid air after continuous spiking. Specimens were fully saturated at $344 \mathrm{~K}, 100 \%$ relative humidity before spiking (see Figure 3, right). - - data for specimens spiked 1, 5, or 25 times between the temperatures $195 \mathrm{~K}$ to $422 \mathrm{~K}, 195 \mathrm{~K}$ to $294 \mathrm{~K}$, or $294 \mathrm{~K}$ to $422 \mathrm{~K}$; solid line represents weight change of unspiked specimens. 


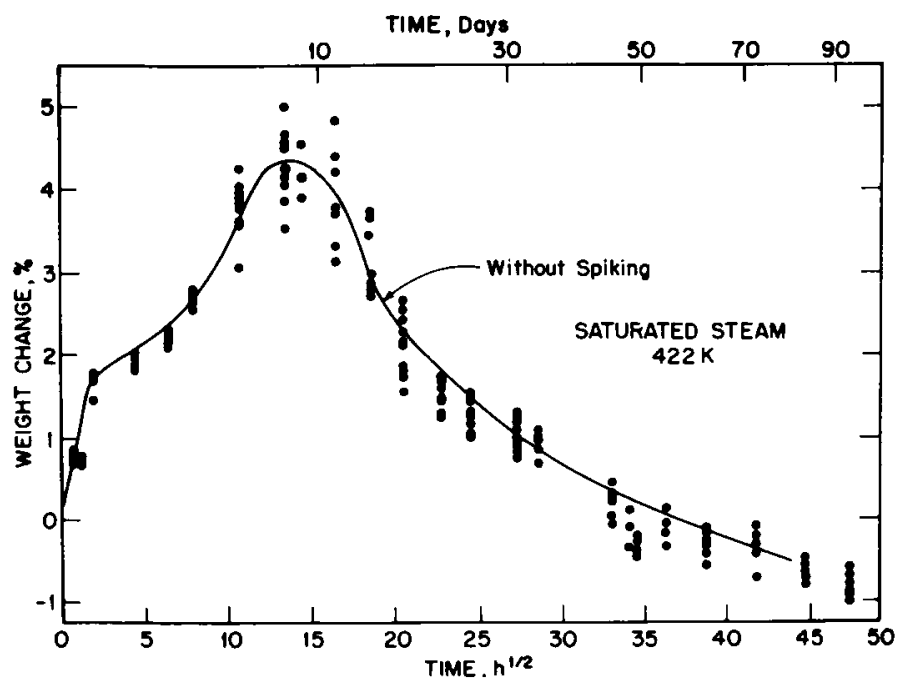

Figure 16. Weight change as a function of time of unidirectional T300/Fiberite 1034 specimens immersed in saturated steam after continuous spiking. Specimens were dry before spiking (see Figure 3, left). • - data for specimens spiked 1, 5, or 25 times between the temperatures $195 \mathrm{~K}$ to $422 \mathrm{~K}, 195 \mathrm{~K}$ to $294 \mathrm{~K}$, or $294 \mathrm{~K}$ to $422 \mathrm{~K}$; solid line represents weight change of unspiked specimens.

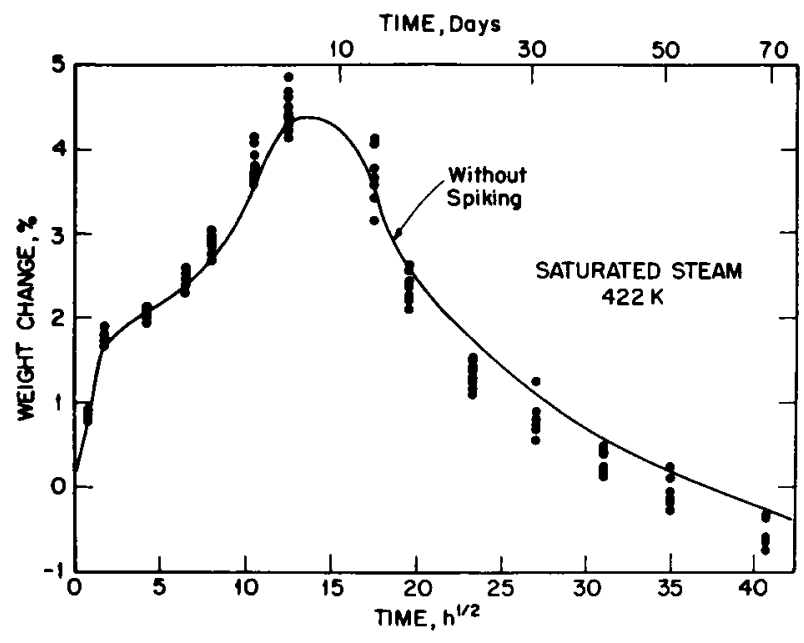

Figure 17. Weight change as a function of time of unidirectional T300/Fiberite 1034 specimens immersed in saturated steam after continuous spiking. Specimens were fully saturated at $344 \mathrm{~K}, 100 \%$ relative humidity before spiking (see Figure 3, right). •- data for specimens spiked 1, 5, or 25 times between the temperatures $195 \mathrm{~K}$ to $422 \mathrm{~K}, 195 \mathrm{~K}$ to $294 \mathrm{~K}$, or $294 K$ to $422 K$; solid line represents weight change of unspiked specimens. 


\section{4) Change in Ultimate Tensile Strength and Buckling Modulus Due to Saturated Steam Exposure}

The ultimate tensile strength and the buckling modulus of specimens exposed to saturated steam were also measured as a function of exposure time. The results of these measurements are given in Figures 18 and 19 both for unidirectional and for $\pi / 4$ specimens. Each of these specimens was first dried and then placed in the steam chamber for the required time. The specimens were then cooled to room temperature and the tensile strengths and buckling moduli were measured. The data in Figures 18 and 19 indicate that neither the ultimate tensile strength nor the buckling modulus was affected appreciably by exposure to the saturated steam. However, some delamination was observed during buckling tests after 435 hours of exposure to saturated steam. These failures occured only with $\pi / 4$ laminates, 56 $\mathrm{mm}$ in length. The longer $\pi / 4$ buckling specimens were not affected.

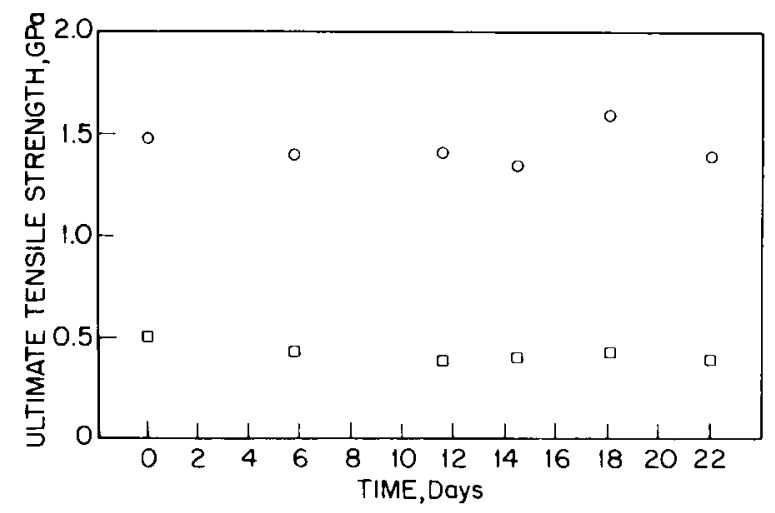

Figure 18. Ultimate tensile strength of T300/Fiberite 1034 as a function of exposure time to saturated steam at $422 \mathrm{~K}$. 0 - unidirectional laminates; $\square-\pi / 4$ laminates.

Thus, it appears that while exposure to a high temperature-high moisture content environment may change significantly the weight change characteristics of the material, it does not alter appreciably such mechanical properties as the ultimate tensile strength or the buckling modulus.

\section{CONCLUSIONS}

The following general conclusions can be drawn on the basis of the present data, obtained with Thornel 300/Fiberite 1034 graphite epoxy composites

1) Thermal spiking does not change significantly the moisture absorption characteristics of the material as represented by the moisture content as a function 


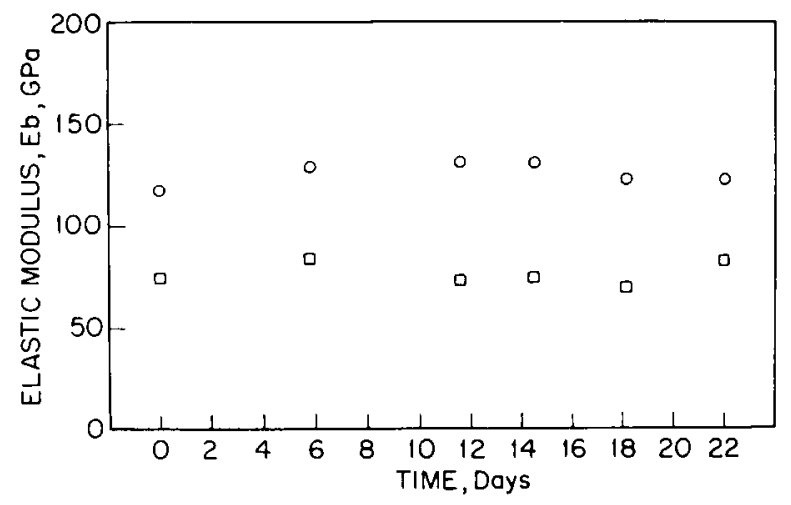

Figure 19. Elastic (buckling) modulus of T300/Fiberite 1034 as a function of exposure time to saturated steam at $422 \mathrm{~K}$. $\circ$ - unidirectional laminates; $\square-\pi / 4$ laminates.

of time, the maximum moisture content, and the transverse diffusivity.

2) Thermal spiking does not reduce either the tensile strength or the buckling modulus of unidirectional or $\pi / 4$ laminates.

3) Immersion in $422 \mathrm{~K}$ saturated steam changes considerably the moisture absorption characteristics of the material causing cracking and, subsequently, material loss.

4) Long term (up to 20 days) immersion in $422 \mathrm{~K}$ saturated steam does not reduce either the ultimate tensile strength or the buckling modulus of either unidirectional or $\pi / 4$ laminates.

The above conclusions apply only to Thornel 300/Fiberite 1034 composites. Imination of the data available for other graphite epoxy composites (see Table 1) provides the following additional information

5) The effect of thermal spiking depends on the composition of the material. Some graphite-epoxy composites are affected more by thermal spiking than $\mathrm{T} 300 / 1034$. The moisture absorption characteristics of T300/5208 laminates seem to be affected particularly by thermal spiking.

6) In most cases the mechanical properties of the material are not reduced significantly by thermal spiking. Fiber dominated properties seem to be especially insensitive to thermal spiking.

\section{APPENDIX}

\section{Autoclave Cure Cycle for T300/1034}

1. Vacuum Bag-insert layup into autoclave at room temperature.

2. Apply full vacuum and contact pressure.

3. Raise temperature to $250^{\circ} \mathrm{F}$ at $3^{\circ} \mathrm{F}$ per minute. 
4. Hold at $250^{\circ} \mathrm{F}$ for 15 minutes. Apply 100 psi.

5. Hold at $250^{\circ} \mathrm{F}$ and 100 psi for 45 minutes.

6. Raise temperature to $350^{\circ} \mathrm{F}$.

7. Hold at $350^{\circ} \mathrm{F}$ for 2 hours.

8. Cool under pressure to below $175^{\circ} \mathrm{F}$.

\section{ACKNOWLEDGMENTS}

The authors wish to thank Dr. C. H. Shen for his help in obtaining some of the continuous spiking data. This work was supported by the United States Air Force Materials Laboratory, Air Force Systems Command, Wright-Patterson Air Force Base, Dayton, Ohio under contract number F33615-75-C-5165.

\section{REFERENCES}

1. R. E. Bohlmann and E. A. Derby, "Moisture Diffusion in Graphite/Epoxy Laminates: Experimental and Predicted," Presented at the 18th Structures, Structural Dynamics and Materials Conference, and at the Conference on Aircraft Composites: The Emerging Methodology for Structural Assurance, San Diego, Calif., March 1977, AIAA Technical Papers Volume A. (A77-25726 10-39) p. 219-226 (1977).

2. T. J. Reinhart, "Air Force Materials Laboratory Perspective," in "The Effects of Relative Humidity and Elevated Temperatures on Composite Structures," (Eds. J. R. Vinson, R. B. Pipes, W. J. Walker and D. R. Ulrich), AFOSR TR-770030, p. 37-97 (1977).

3. E. L. McKague, Jr., J. E. Halkias and J. D. Reynolds, "Moisture in Composites: The Effect of Supersonic Service on Diffusion," J. Composite Materials, Vol. 9, p. 2.

4. K. G. Kibler, "Effects of Moisture and Elevated Temperature on 5208/T300," in "The Effects of Relative Humidity and Elevated Temperature on Composite Structures," (Eds. J. R. Vinson, R. B. Pipes, W. J. Walker and D. R. Ulrich), AFSOR TR-770030, p. 190-211 (1977).

5. J. M. Augl, "Research on Composite Materials," Quarterly Report to the Naval Air Systems Command (1975).

6. C. Y. Lundemo and S.E. Thor, "Influence of Environmental Cycling on the Mechanical Properties of Composite Materials," J. Composite Materials, Vol. 11, p. 276.

7. R. L. Stoecklin, "737 Graphite Composite Flight Spoiler Flight Service Evaluation," NASA CR-144984, May 1976.

8. R. E. Trabocco and M. Stander, "Effect of Natural Weathering on the Mechanical Properties of Graphite/Epoxy Composite Materials," Environmental Effects on Advanced Composite Materials, ASTM STP 602, American Society for Testing and Materials, 1976, p. 67.

9. R. Delasi and J. B. Whiteside, "Effect of Moisture on Epoxy Resins and Composites," Advanced Composite Materials - Environmental Effects, ASTM STP 658, J.R. Vinson, Ed., American Society for Testing and Materials, 1978, p. 2.

10. C. E. Browning and J. T. Hartness, "Effects of Moisture on the Properties of High-Performance Structural Resins and Composites," Composite Materials: Testing and Design (Third Conference), ASTM STP 546, American Society for Testing and Materials, 1974, p. 284.

11. J. L. Camahort, E. H. Rennhack and W. C. Coons, "Effects of Thermal Cycling Environment on Graphite/Epoxy Composites," Environmental Effects on Advanced Composite Materials, ASTM STP 602, American Society for Testing and Materials, 1976, p. 37.

12. C.-H. Shen and G. S. Springer, "Moisture Absorption and Desorption of Composite Materials," J. Composite Materials, Vol. 10, p. 2. 
13. C.-H. Shen and G. S. Springer, "Environmental Effects on the Elastic Moduli of Composite Materials," J. Composite Materials, Vol. 11, p. 250.

14. J, M, Whitney and C. E. Browning, "Some Anomalies Associated with Moisture Diffusion in Epoxy Matrix Composite Materials," Advanced Composite Materials - Environmental Effects, ASTM STP 658, J.R. Vinson, Ed., American Society for Testing and Materials, 1978, p. 43. 